\title{
The devil in the deep: expanding the known habitat of a rare and protected fish
}

${ }^{1}$ School of Biological

Sciences, University

of Wollongong, NSW, Australia.

Corresponding author E-mail:fishthinkers@ gmail.com

${ }^{2}$ Fish Thinkers Research Group, 11 Riverleigh Avenue, Gerroa, NSW 2534, Australia.

${ }^{3}$ School of Biological, Earth and Environmental Science, University of New South Wales, NSW 2052 Australia

${ }^{4}$ Fisheries Research, New South Wales

Department of Primary Industries, 4 Woollamia Road, Huskisson, NSW, Australia

${ }^{5}$ School of Life and Environmental Sciences, University of Sydney, NSW 2006 Australic

\author{
Lachlan C. Fetterplace ${ }^{1,2}$, John W. Turnbull ${ }^{3}$, Nathan A. Knott ${ }^{4}$, Natasha A. Hardy ${ }^{5}$
}

\section{ABSTRACT}

The accepted geographic range of a species is related to both opportunity and effort in sampling that range. In deepwater ecosystems where human access is limited, the geographic ranges of many marine species are likely to be underestimated. A chance recording from baited cameras deployed on deep uncharted reef revealed an eastern blue devil fish (Paraplesiops bleekeri) at a depth of $51 \mathrm{~m}$ and more than $2 \mathrm{~km}$ further down the continental shelf slope than previously observed. This is the first verifiable observation of eastern blue devil fish, a protected and endemic southeastern Australian temperate reef species, at depths greater than the typically accepted depth range of $30 \mathrm{~m}$. Knowledge on the ecology of this and many other reef species is indeed often limited to shallow coastal reefs, which are easily accessible by divers and researchers. Suitable habitat for many reef species appears to exist on deeper offshore reefs but is likely being overlooked due to the logistics of conducting research on these often uncharted habitats. On the basis of our observation at a depth of $51 \mathrm{~m}$ and observations by recreational fishers catching eastern blue devil fishes on deep offshore reefs, we suggest that the current depth range of eastern blue devil fish is being underestimated at $30 \mathrm{~m}$. We also observed several common reef species well outside of their accepted depth range. Notably, immaculate damsel (Mecaenichthys immaculatus), red morwong (Cheilodactylus fuscus), mado (Atypichthys strigatus), white-ear (Parma microlepis) and silver sweep (Scorpis lineolata) were abundant and recorded in a number of locations at up to a depth of at least $55 \mathrm{~m}$. This underestimation of depth potentially represents a large area of deep offshore reefs and micro-habitats out on the continental shelf that could contribute to the resilience of eastern blue devil fish to extinction risk and contribute to the resilience of many reef species to climate change.

\section{KEYWORDS}

Natural history, Biogeography, Range expansion, Eastern blue devil fish, BRUV, SCUBA, Recreational fishing, Temperate reef Depth range, Patch reef

(c))BY-NC-ND $\odot 2018$ Lachlan C. Fetterplace et al.

This is an open access article distributed under the Creative Commons Attribution-NonCommercial-NoDerivs license

\section{INTRODUCTION}

In October 2013, we were two months into undertaking video sampling of fish communities on poorly studied marine softsediment environments, off the southeast coast of Australia. We sampled around $3 \mathrm{~km}$ offshore using baited remote underwater video stations (BRUVS; Fig. 1) in relatively deep water (50-60 $\mathrm{m}$ ), beyond the ability to effectively sample using SCUBA. We dropped cameras on what we thought to be sand, but that turned out to be uncharted low-profile patch reef, full of overhangs and crevices.

For our purposes, samples on non-target habitat (reefs) are considered 'failed', typically stored on hard drives and left to gather dust at the back of a laboratory. This time though, perhaps because the seascape was so interesting, we went through the entire hour-long video sample from a deep offshore reef. And there it was, the unmistakeable electric blue colouring, white stripes and shy emergence of an eastern blue devil fish (Paraplesiops bleekeri) from a crevice to investigate a baited camera. This observation occurred at nearly triple their previously recorded depth (at $51 \mathrm{~m}$ ) and more than $2 \mathrm{~km}$ further down the continental shelf slope than previously observed (video here).

Eastern blue devil fish are protected off the coast of eastern Australia under the Fisheries Management Act 1994. They are rare and endemic to eastern Australian coastal reefs and considered vulnerable to extraction for the aquarium industry (NSW DPI 2006). Despite this, little is known about them beyond taxonomic and descriptive information. In particular, little is known about the full extent of their geographic and depth range, information that is important to understanding the extinction risk, critical habitat and management needs of vulnerable and endemic species (Purcell et al. 2004).

The observation of eastern blue devil fish, a demersal (bottom dwelling) coastal reef species, on deep offshore reefs 


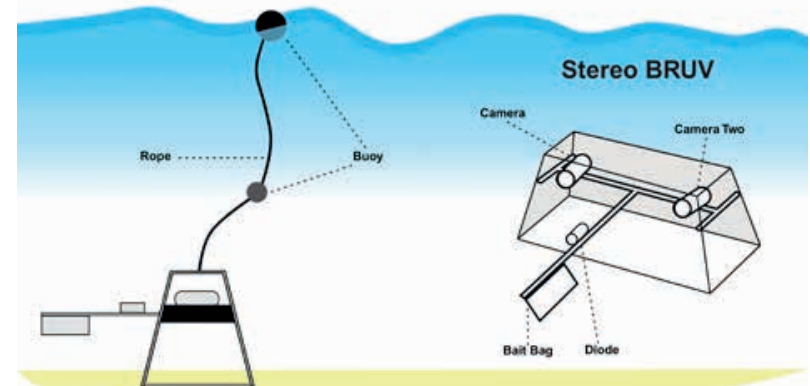

Figure 1: Baited remote under water video stations (BRUVS) are often used to sample fish communities (taken from Fetterplace and Rees 2017, CC BY 4.0). BRUVS are lowered to the sea floor (or to the desired depth if sampling pelagic fishes e.g. Rees et al. 2015 for an interesting example) and left to record visiting species without the need for an operator to be continuously present. This allows a number of samples to be taken simultaneously by deploying numerous BRUVS at the same time over a number of sites. Other advantages of BRUVS include that it avoids potential behavioural changes fish may have in the presence of divers, provides a permanent record, is non-extractive, and can survey at depths, times and in weather conditions that are dangerous for divers. The use of newer paired camera stereo BRUVS also allows the accurate measurement of fish size (for a detailed review of BRUVS methodology see Whitmarsh et al. 2017). was unusual, primarily because of the observed depth and distance from the coast. Eastern blue devil fish are charismatic yet shy (Fig. 2) cryptic fish previously recorded in shallow coastal waters and on inshore rocky reefs of 1-17 m (Edgar and StuartSmith 2018) where they are found in caves, crevices and under ledges (Kuiter 2000, NSW DPI 2006). Eastern blue devil fish are listed as having a possible range down to $30 \mathrm{~m}$ (e.g. Kuiter 2000, NSW DPI 2006, Gomon et al. 2008); however, there are no records on Reef Life Survey (RLS), a global database for reef biota, at depths below $17.2 \mathrm{~m}$. In fact, most RLS records are from much shallower depths, with an average depth recorded on the RLS database of $9.1 \mathrm{~m}$ (Edgar and Stuart-Smith 2014, Edgar and Stuart-Smith 2018).

We know of no historical records in Australian museums or databases of eastern blue devil fish from deeper than $30 \mathrm{~m}$ either. Owing to a combination of their protected status and the complex terrain they inhabit, commercial fishers are unlikely to come across them, as trawling is avoided on these areas because of the risk of damage to nets. The vast majority of sightings and records of eastern blue devil fish are reported from divers and researchers. The accepted depth range of eastern blue devil fish and many coastal reef fish coincides with the recreational dive limits of $\sim 30 \mathrm{~m}$, despite the fact that

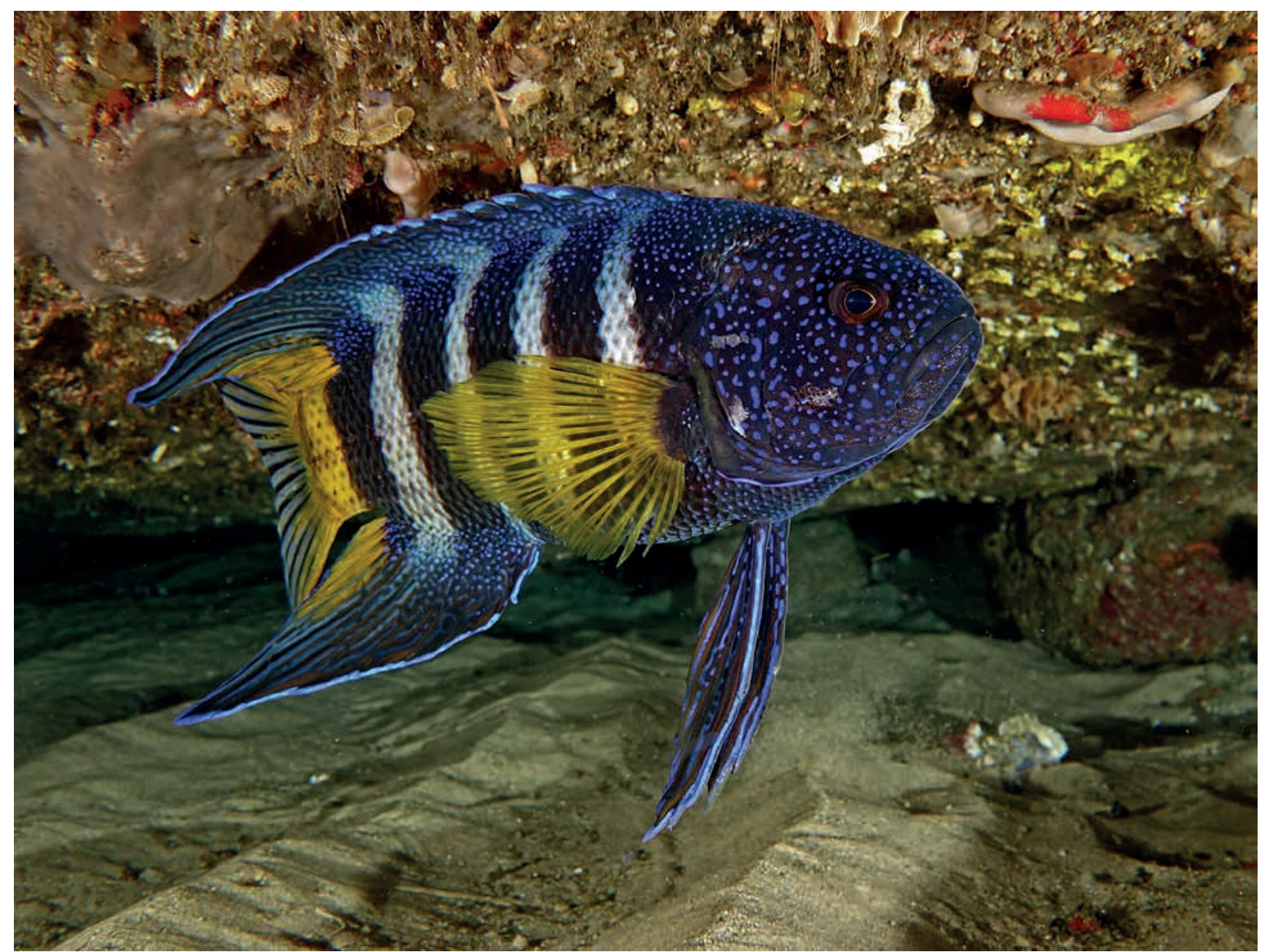

Figure 2: The eastern blue devil (Paraplesiops bleekeri) is a temperate cave-associated species that would not look out of place on a tropical reef. Brightly coloured and a prize sighting for divers; they are protected in New South Wales (Australia) waters because of their natural rarity and low abundance. (Photographer: John Turnbull: CC BY-NC-SA 2.0). 
Box 1: Extending our knowledge of deep reef assemblages The eastern blue devil fish was not the only species that we recorded outside its known depth range. After the initial unexpected observation of the eastern blue devil fish, we identified the species present on another 17 additional 'failed' reef BRUVS samples collected across an approximately $75 \mathrm{~km}$ stretch of coastline from Jervis Bay to Bawley Point, NSW, Australia (data available at Fetterplace and Knott 2018). It soon became clear that a number of more common species were also captured on camera outside their previously recorded depth range (Fig. 3, Table 1). Notably, several common reef species, such as immaculate damsel, red morwong, mado, white-ear and silver sweep, are all listed as occurring down to $30 \mathrm{~m}$, yet were present on $50-89 \%$ of deepwater reef samples (Fig. 3, Table 1). Other species were observed $<15$ $\mathrm{m}$ outside their accepted depth range, including crimson-banded wrasse (Notolabrus gymnogenis) on $17 \%$ of samples (Fig. 3, Table 1). We also found evidence that the depth range of one species, redbanded grubfish (Parapercis binivirgata), ), includes much 'shallower' areas than listed in the scientific literature. This species is listed as occurring in waters deeper than $86 \mathrm{~m}$, however, was present at a depth of $50 \mathrm{~m}$ on $39 \%$ of reef samples (Table 1). These observations further support our hypothesis that the depth range of many other coastal reef species is likely underestimated.

Once off the reef edge, the fish communities found on the surrounding sandy areas begin to change and are very different to those on the reef (Schultz et al. 2012). Our study area is no exception; the patch reefs at a depth of $50 \mathrm{~m}$ tend to be dominated by a range of more colourful or conspicuous species, whilst the surrounding sand habitats sampled in Fetterplace (2018) are dominated by flatheads (Platycephalidae), which use camouflage and burial in the sand to ambush prey. In contrast to the reef samples, none of the species encountered in comprehensive sampling on soft sediments at a depth of 50-60 m was outside its depth range (Table 1). Species that occur on sand are much more likely to have been caught in scientific or commercial trawling and the capture depths then included in the scientific records.

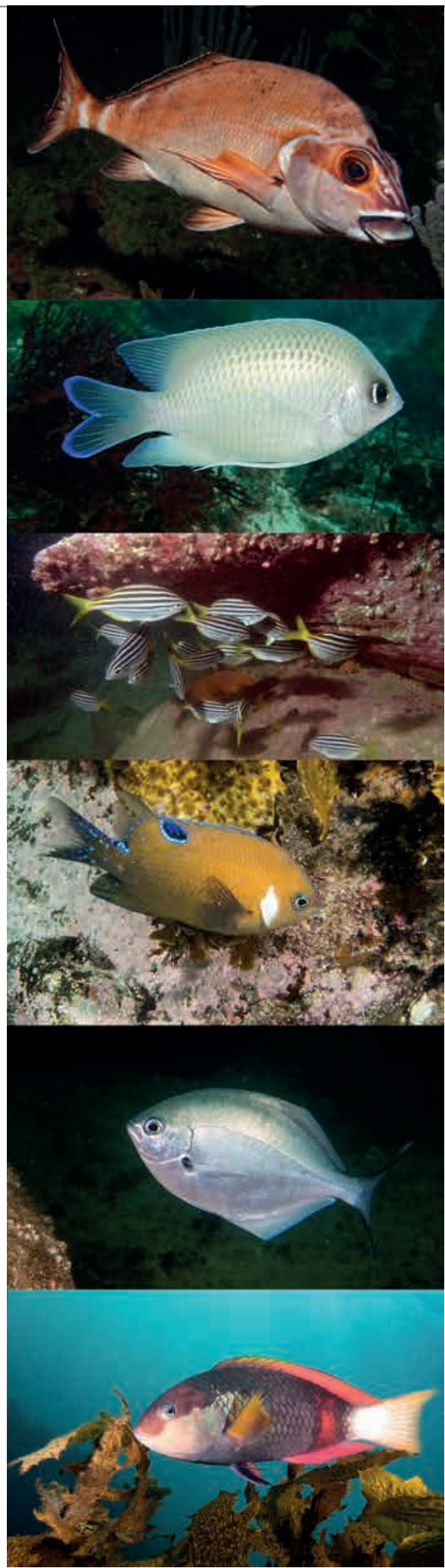

Figure 3: Five species (photos from top to second from the bottom are red morwong, immaculate damsel, mado, white-ear and silver sweep) that are common on shallow reefs and previously had an accepted depth range of $<30 \mathrm{~m}$ were observed regularly on deeper reefs in this study (>50 m). Crimson-banded wrasse (bottom photo) was also observed outside their depth range on a small number of samples. (Photographer: John Turnbull: CC BY-NC-SA 2.0). 


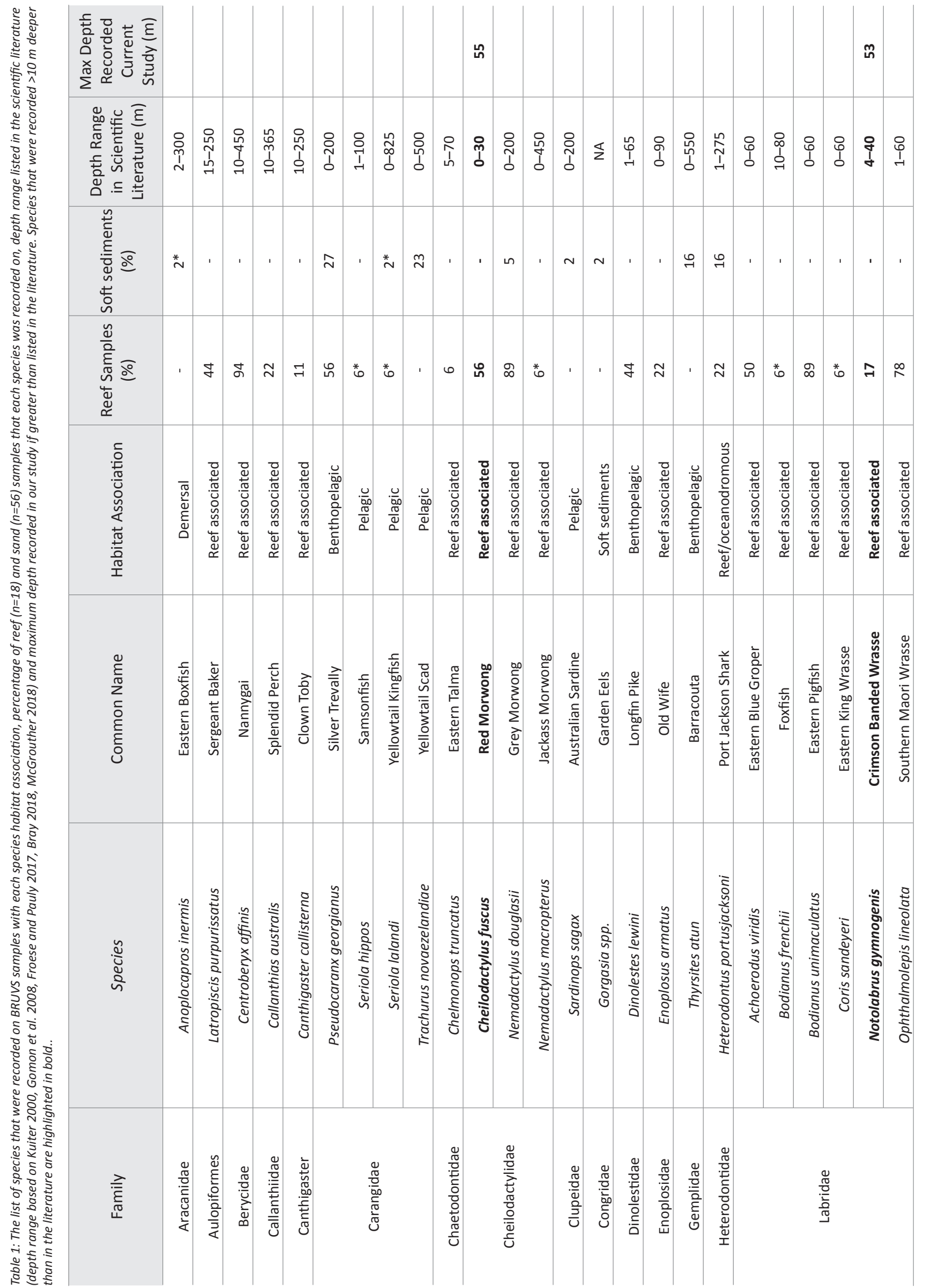




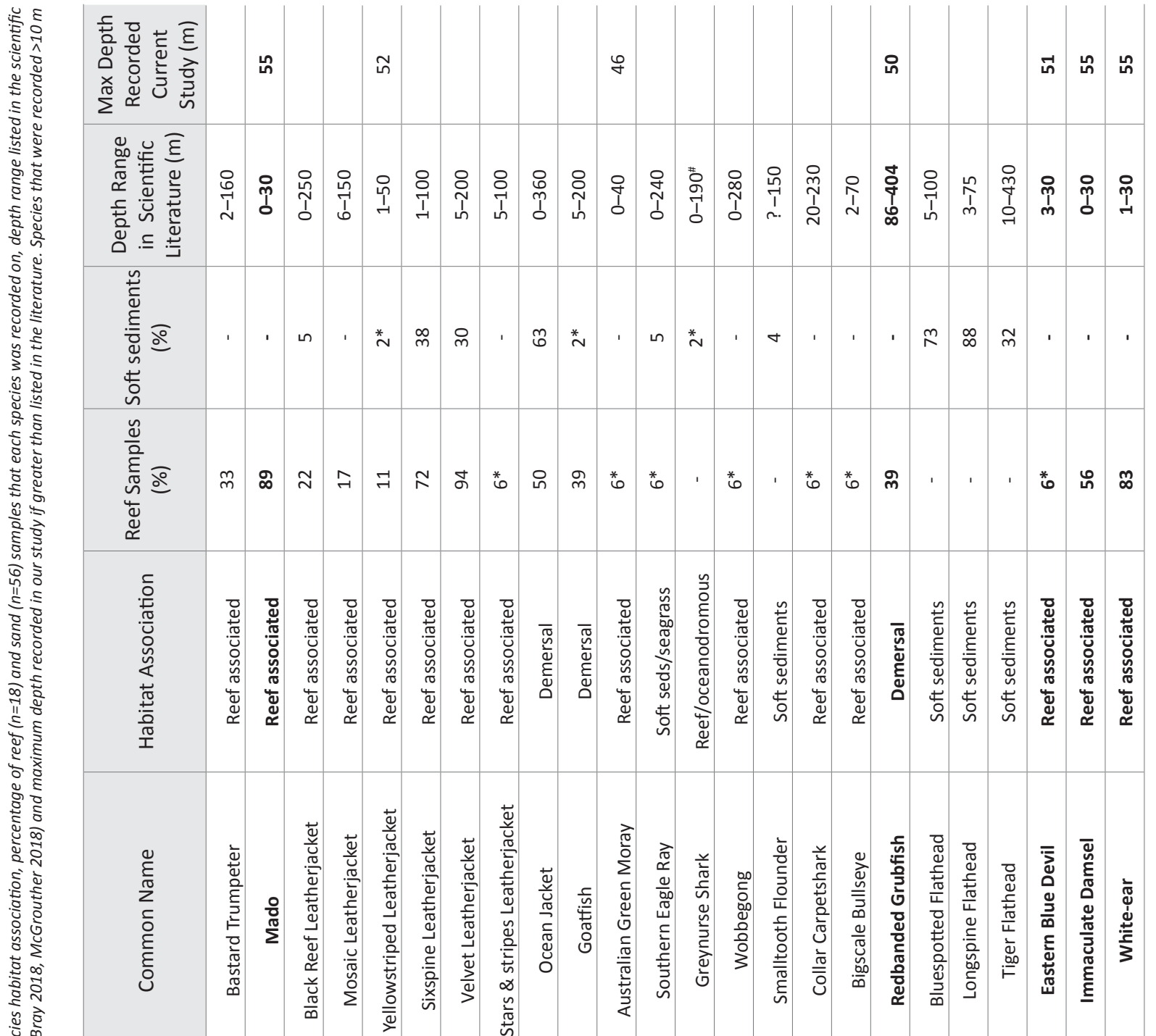

ปั้

$\frac{5}{5}$

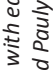

के

है

>

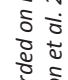

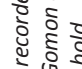

ॐूँ

ำ

要䨔

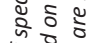

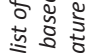

है के

造

है

ชิ ขั

ปัँ

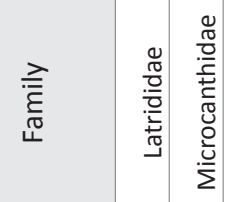

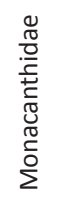

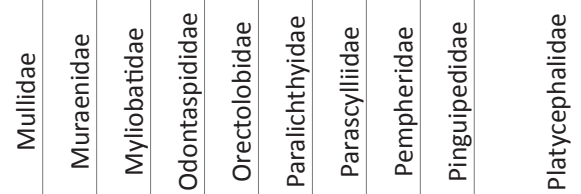

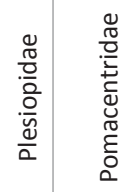




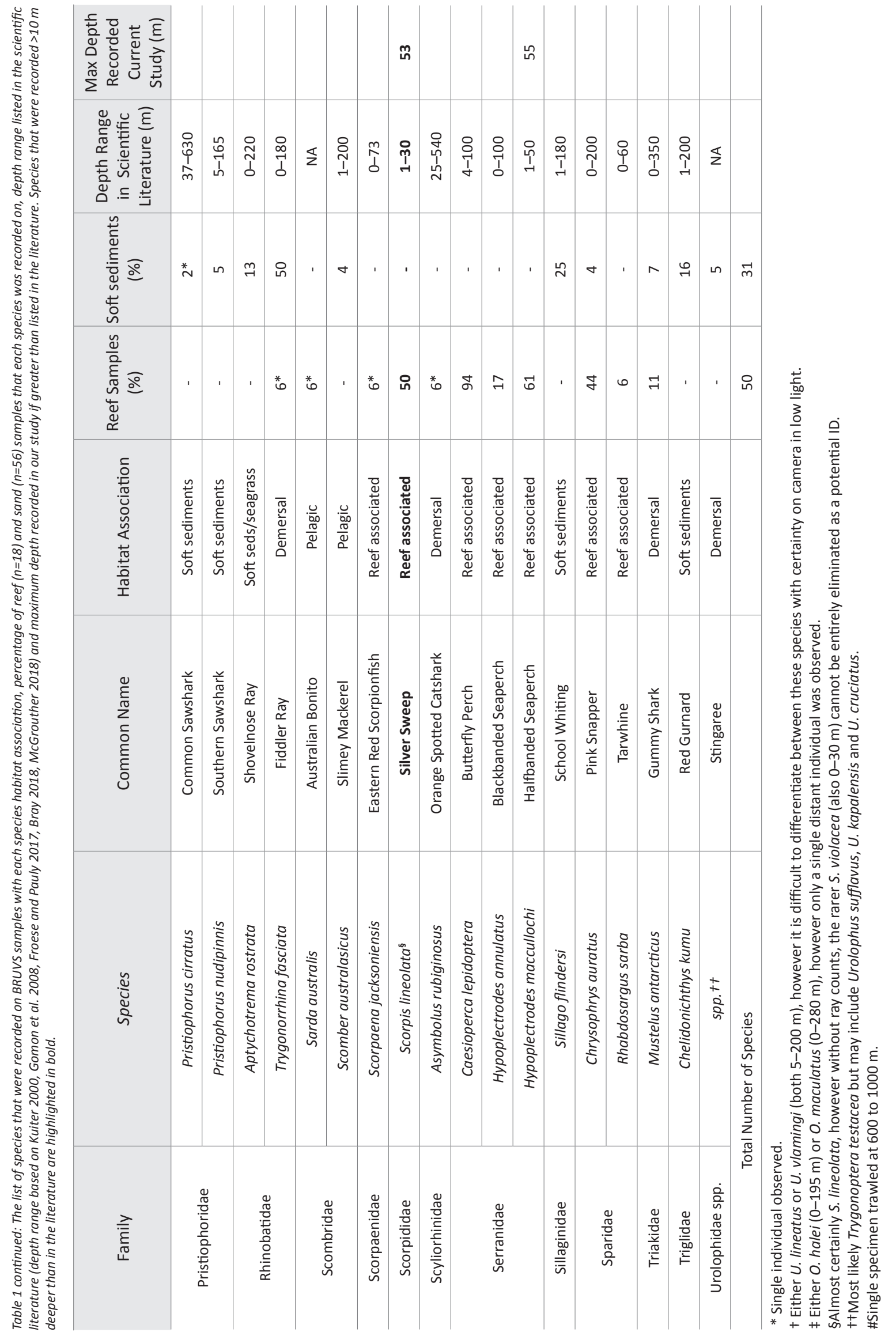


suitable habitat likely exists on deeper offshore reefs (Purcell et al. 2014). Indeed, we also observed common reef species, including immaculate damsel (Mecaenichthys immaculatus), red morwong (Cheilodactylus fuscus), mado (Atypichthys strigatus), white-ear (Parma microlepis) and silver sweep (Scorpis lineola$t a$ ) on reefs at a depth of 53-55 m, well outside their reported depth range (Box 1). These observations further support our hypothesis that the depth range of eastern blue devil fish and also other coastal reef species is likely being underestimated.

Our observation, using baited cameras, may be the only verifiable video footage ever taken of eastern blue devils at this depth. However, a confirmed capture from $48 \mathrm{~m}$ on a charter fishing boat of an eastern blue devil fish occurred off the coast of Sydney in February 2018 (see Appendix 1). Recreational fishers also report accidentally catching eastern blue devil fishes on lines on patch reefs that we know to be in waters deeper than $40 \mathrm{~m}$. Often the fishermen did not know what they were and posted a description or photos for identification on online fishing forums (L. Fetterplace, pers. obs.). On investigation, we were able to confirm that a number of these photos were of eastern blue devil fish. However, recreational fishers can distrust scientists, are often not consulted, and are guarded about the locations of their fishing spots. Despite this, their knowledge is potentially significant in corroborating scientific observations and increasing sampling effort of rare species. Here, a report from a charter fishing operator and anecdotal observations by recreational fishers of eastern blue devil fishes on deep reefs further suggest that the geographic and depth range of this protected species are currently being underestimated.

The observation of eastern blue devil fish, a coastal reef species, on deep reefs out on the continental shelf raises several questions regarding how it came to be there. We know these fish are site-attached, cryptic predators inhabiting coastal rocky reefs, they are nocturnal demersal predators and do not move into the upper water column (Kuiter 2000). The particular reef on which the eastern blue devil fish was sighted is surrounded by large areas of exposed sandy seafloor and the gradient in this area means that this fish would have had to move horizontally roughly $2 \mathrm{~km}$ from the nearest reefs in their current accepted depth range. Adults of many demersal reef-attached species do not move across large areas of sand (Chapman and Kramer 2000, Turgeon et al. 2010), and for these species, sandy areas can effectively form barriers to adult movement. We know of no examples of adult eastern blue devil fish ever being recorded moving across soft sediments (or any non-reef habitats). All these constraints on movement suggest that the observed adult eastern blue devil fish settled during its larval stage and grew to adulthood on the deep offshore reef sampled in this study.

On the basis of our report and corroborating evidence from recreational fishers, a broader interdisciplinary effort to research the range of eastern blue devil fish as well as many other coastal reef species is warranted. Deeper water research will greatly benefit from collaborating with fishers and citizen science programmes (e.g. Redmap and Australasian fishes project). Extending the range of eastern blue devil fish from a thin strip along the coast to $2-5 \mathrm{~km}$ offshore opens up a vast area of potential habitat sites that have not been investigated. If the range of the eastern blue devil fish can be further corroborated down to at least $50 \mathrm{~m}$ and potentially well beyond, this would significantly expand the known habitat of a rare and protected fish. This knowledge can help give conservation measures for this species the greatest chance of success, whilst also benefitting the management of deeper offshore reefs.

How commonly eastern blue devil fish occur on deeper reefs is unknown, as is the relative importance of deep reefs to eastern blue devil fish and many other reef species. The implications are exciting. Have these fish always been on deep complex reefs (>40 $\mathrm{m}$ ) and we simply have not detected them? Could deep reef habitats act as cooler water refugia (HoeghGuldberg et al. 2017, Kavousi and Keppel 2018), increasing the resilience of a rare and protected temperate reef species against climate change? Numerous climate-driven range shifts have been documented globally (Figueira and Booth 2010, Poloczanska et al. 2013, Pecl et al. 2017), and it is feasible that eastern blue devil fishes and other reef fishes may be shifting their range both in latitude and depth. Without further sampling of deeper reefs on the continental shelf, we will not know the extent and range of the deeper populations of eastern blue devil fish, and how they and other reef fishes are being affected by climatic changes in an ocean warming hotspot (Sunday et al. 2015).

These sightings remind us yet again how little we know of the deeper oceans, and the dangers of restricting conservation and management efforts to well-studied shallow, coastal and relatively 'accessible' environments. Indeed, we show that eastern blue devil fish and a number of more common species are using deep reefs well outside their commonly accepted depth range. Many other reef fish species most probably occur on deeper reefs in Australia and in coastal waters globally (Purcell et al. 2014), and we are simply not yet looking deep enough.

\section{DATA AVAILABILITY}

The site specific species presence or absence for each deep reef BRUVS sample (summarised in Table 1) and the accepted depth ranges for each species from all reference sources consulted, is available under a CC BY 4.0 licence as a dataset: Offshore Reef Fishes of South Coast NSW (Fetterplace and Knott 2018).

Ethical Note: The sampling methods in this study were approved by the New South Wales Department of Primary Industries (Fisheries) animal care and ethics committee, ACEF Ref: 10/09.

Acknowledgements: Funding and in-kind support for the field work was provided by the NSW Department of Primary Industries and the University of Wollongong. This research is also 
supported by the Australian Government Research Training Program Scholarships. We thank Prof Andy Davis, members of the Davis Lab, staff at Jervis Bay Marine Park and Batemans Marine Park for their assistance in the field. We also thank Margie Andréason and Cameron Fetterplace who provided valuable comments and suggestions that greatly improved the manuscript and Sascha Schulz, Sue Newson and Mark McGrouther for their assistance and helpful discussion of species identification and current range. We also acknowledge the efforts of reviewer Dr Ladislav Pekarik and one other anonymous reviewer who helped to improve the initial manuscript.

\section{References}

Australasian Fishes Project. (2018). "Australasian Fishes Project (iNaturalist)." Retrieved Jan 1, 2018, from https://www.inaturalist.org/ projects/australasian-fishes.

Bray, D. J. (2018). "Fishes of Australia." Retrieved 01 Jan, 2018, from http://fishesofaustralia.net.au.

Chapman, M. R. and Kramer, D. L. (2000). "Movements of Fishes Within and Among Fringing Coral Reefs in Barbados." Environmental Biology of Fishes 57(1): 11-24.

Edgar, G. J. and Stuart-Smith, R. D. (2014). "Systematic global assessment of reef fish communities by the Reef Life Survey program." Scientific Data 1: 140007.

Edgar, G. J. and Stuart-Smith, R. D. (2018). "Reef Life Survey (RLS): Global reef fish dataset. Institute for Marine and Antarctic Studies (IMAS)." Retrieved Jan 2018, from https://reeflifesurvey.imas. utas.edu.au/static/landing.html.

Fetterplace, L. C. (2018). The ecology of temperate soft sediment fishes: Implications for fisheries management and marine protected area design. Doctor of Philosophy thesis, University of Wollongong.

Fetterplace, L. C. and Knott, N. A. (2018). Dataset: Offshore Reef Fishes of South Coast NSW. figshare.

Fetterplace, L. C. and Rees, M. J. (2017). "Baited Remote Underwater Video: Images and Figures." figshare.

Figueira, W. F. and Booth, D. J. (2010). "Increasing ocean temperatures allow tropical fishes to survive overwinter in temperate waters." Global Change Biology 16(2): 506-516.

Froese, R. and Pauly, D. (2017). "World Wide Web electronic publication." Retrieved 1/01/2018, from www.fishbase.org.

Gomon, M. F., Bray, D. J. and Kuiter, R. H., Eds. (2008). Fishes of Australia's southern coasts, New Holland.

Hoegh-Guldberg, O., Poloczanska, E. S., Skirving, W. and Dove, S. (2017). "Coral Reef Ecosystems under Climate Change and Ocean Acidification." Frontiers in Marine Science 4(158).
Kavousi, J. and Keppel, G. (2018). "Clarifying the concept of climate change refugia for coral reefs." ICES Journal of Marine Science 75(1): 43-49.

Kuiter, R. H. (2000). Coastal Fishes of South-eastern Australia, Gary Allen.

McGrouther, M. (2018). "Fish Web Pages." Australian Museum.Retrieved Jan 01, 2018, from http://australianmuseum.net.au.

NSW DPI (2006). Eastern blue devil fish (Paraplesiops bleekeri), primefacts 165 June. NSW Department Of Primary Industries.

Pecl, G. T., Araújo, M. B., Bell, J. D., Blanchard, J., Bonebrake, T. C., Chen, I.C., et al. (2017). "Biodiversity redistribution under climate change: Impacts on ecosystems and human well-being." Science 355(6332).

Poloczanska, E. S., Brown, C. J., Sydeman, W. J., Kiessling, W., Schoeman, D. S., Moore, P. J., et al. (2013). "Global imprint of climate change on marine life." Nature Climate Change 3: 919.

Purcell, S. W., Clarke, K. R., Rushworth, K. and Dalton, S. J. (2014). "Defining Critical Habitats of Threatened and Endemic Reef Fishes with a Multivariate Approach." Conservation Biology 28(6): 1688-1698.

Rees, M. J., Knott, N. A., Fenech, G. V. and Davis, A. R. (2015). "Rules of attraction: enticing pelagic fish to mid-water remote underwater video systems (RUVS)." Marine Ecology Progress Series 529: 213-218.

Schultz, A. L., Malcolm, H. A., Bucher, D. J. and Smith, S. D. A. (2012). "Effects of Reef Proximity on the Structure of Fish Assemblages of Unconsolidated Substrata." PLoS ONE 7(11): e49437.

Sunday, J. M., Pecl, G. T., Frusher, S., Hobday, A. J., Hill, N., Holbrook, N. J., et al. (2015). "Species traits and climate velocity explain geographic range shifts in an ocean-warming hotspot." Ecology Letters 18(9): 944-953.

Turgeon, K., Robillard, A., Grégoire, J., Duclos, V. and Kramer, D. L. (2010). "Functional connectivity from a reef fish perspective: behavioral tactics for moving in a fragmented landscape." Ecology 91(11): 3332-3342.

Whitmarsh, S. K., Fairweather, P. G. and Huveneers, C. (2017). "What is Big BRUVver up to? Methods and uses of baited underwater video." Reviews in Fish Biology and Fisheries 27(1): 53-73.

\section{APPENDIX 1. CHARTER BOAT CAPTURE OF EASTERN BLUE DEVIL FISH}

On the 17 February 2018, a Sydney-based charter boat 'FishFinder' caught an adult eastern blue devil fish in $48 \mathrm{~m}$ of water outside of Sydney Harbour in the vicinity of South Head. The fish appeared to be showing signs of barotrauma; however, it was released and reportedly swam away strongly. At the time of publication, a photo is available on the charter boats social media pages here. 